\title{
ETICA PRESCRIERII OFF-LABEL A MEDICAMENTELOR LA COPII. DILEMA SILDENAFILULUI
}

\author{
Laszlo-Zoltan Sztankovszky ${ }^{1}$, Magdalena Iorga ${ }^{1}$, Cristian Gheonea ${ }^{2}$, \\ Georgiana Russu ${ }^{3}$ \\ ${ }^{1}$ Departamentul de Medicină Preventivă şi Interdisciplinară, \\ Universitatea de Medicină şi Farmacie, ,, Gr. T. Popa “, Iaşi \\ ${ }^{2}$ Clinica de Pediatrie, Universitatea de Medicină şi Farmacie, Craiova \\ ${ }^{3}$ Secția Cardiologie Pediatrică, Spitalul de Urgență pentru Copii ,,Sf. Maria “, Iaşi
}

\begin{abstract}
REZUMAT
Prescripția „off-label“ reprezintă administrarea medicamentelor pe o cale neaprobată, într-o formulare sau doză neaprobată la copii, sau sub intervalul de vârstă indicat pe prospectul aprobat al produsului. Cu toate acestea, tratamentul cu indicații off-label este un fenomen larg răspândit în clinicile de pediatrie. Deoarece multe dintre medicamentele prescrise nu au fost testate în mod adecvat la copii, această populație de pacienți rămâne vulnerabilă. Pe de o parte, folosirea indicațiilor off-label la copii determină o mulțime de controverse, pe de altă parte, fără această posibilitate, unii pacienți ar putea fi lipsiți de şansa de a fi tratați. Lucrarea prezintă amplitudinea fenomenului de prescriere a medicamentelor cu indicații off-label la copii, evaluată în studii ştiințifice din SUA şi Europa. În multitudinea de medicamente prescrise off-label la copii se înscrie şi Sildenafil. Autorii îşi propun prezentarea situației din România cu privire la medicamentul Sildenafil şi utilizarea acestuia în unitățile de cardiologie pediatrică.
\end{abstract}

Cuvinte cheie: etică, medicamente, copii, prescriere, off-label

\section{INTRODUCERE}

În accepțiunea actuală, copilăria acoperă doar 16 ani, restul perioadei de viață fiind reprezentată de perioada adultă şi cea cuprinsă între 60-80 de ani. Conform definiției termenului „copil“ adoptată de Convenția privind drepturile copilului, copilul este o persoană sub vârsta de 18 ani. Conform liniilor directoare ale Conferinței Internaționale pentru Armonizare (ICH), trebuie să distingem între nou-născuți (naştere -27 de zile), sugari (28 de zile -23 de luni), copii (2-11 ani) şi adolescenți (12-18 ani) (1).

Împreună cu femeile gravide, nou-născuții, copiii şi sugarii rămân o categorie denumită orfani terapeutici, pentru că multe medicamente au limite de vârstă sau chiar contraindicații pentru aceste categorii vulnerabile. Evaluarea potențialului de si- guranță al unei prescripții off-label este considerată probabil, aspectul cel mai provocator pentru pediatru. Principalele surse de informații pentru prescrierea de medicamente sunt: $A M A$ evaluarea medicamentelor, Farmacopeea Statelor Unite ale Americii, literatura medicală, diverşi furnizori de informații de farmacologie/farmacologie clinică, US Food and Drug Administration (FDA), surse de informare despre medicamente ale diverselor companii farmaceutice, reprezentanții medicali ai companiilor farmaceutice şi Physicians' Desk Reference (PDR). Aproape $70 \%$ din întregul PDR, fie nu are nici o informație de dozare existentă pentru pacienți pediatrici, fie are declarații explicite că siguranța şi eficacitatea la copii nu au fost determinate. În cea mai bună situație, sunt menționate limitări de vârstă din cauza lipsei de informații de dozare pentru sugari şi copii (2). 
Chiar dacă o parte consistentă din literatura de specialitate şi de cercetare a încercat să identifice diferite dileme referitoare la folosirea medicamentelor în tratamentul minorilor (referindu-se la studii efectuate, prescrierea sau consumul de medicamente în temeiul legislației diferitelor țări) şi unele măsuri au fost adoptate pentru a reglementa această problemă, provocarea rămâne deschisă.

Regulamentul (CE) nr. 1901/2006 al Parlamentului European şi a Consiliului din 12 decembrie 2006 privind produsele medicamentoase pentru uz pediatric recomandă ca medicamentele să fie etic cercetate şi puse la dispoziție pentru copii cu vârsta 0-17 ani. (3)

\section{UTILIZAREA OFF-LABEL A MEDICAMENTELOR LA COPII}

Utilizarea medicamentelor neautorizate sau cu indicații off-label în tratarea copiilor este o practică comună atât în spitale, cât şi în comunitate. Această problemă provine de la faptul că cercetarea pentru stabilirea eficacității şi siguranței medicamentelor la copii nu a fost efectuată din cauza unor probleme de natură etică, din cauza dificultăților logistice, financiare şi juridice. (4)

Nivelul expunerii la medicamentele prescrise este important la toate vârstele, dar cu rata cea mai mare în copilăria timpurie. Anumite cercetări susțin necesitatea unor studii epidemiologice pentru a evidenția motivul prescrierii de medicamente offlabel la copii, alegerea dozei zilnice şi a ritmului de administrare şi evaluarea efectelor farmacologice. $(5,37)$

Copiii nu sunt incluşi în studii clinice din motive etice şi pentru că obținerea consimțământului informat de la părinți este un proces foarte complex, părinții fiind cei care trebuie să decidă în numele copilului lor. În încercarea de a se adapta la această situație, pediatrii şi părinţii optează mai degrabă pentru îngrijirea standard, decât pentru participarea la studii clinice. (6)

În condiții obişnuite copiii sunt excluşi din studiile clinice privind molecule noi cu efect terapeutic. $\mathrm{Cu}$ toate acestea, atunci când medicamentul este aprobat pentru comercializare de către autorități, este doar o chestiune de timp înainte ca medicii să utilizeze medicamentul la pacienții pediatrici. S-a dovedit că practica de a prescrie la copii medicamente cu indicații off-label se regăseşte la aproximativ 50\% dintre toți medicii. (7) Prescripția offlabel înseamnă că medicamentele sunt administrate pe o cale neaprobată, într-o formulare sau doza neaprobată la copii, sau sub intervalul de vârstă indicat pe prospectul aprobat al produsului. Pe de o parte, fără această variantă, copilul suferind ar putea fi lipsit de şansa de a fi tratat. Pe de altă parte, administrarea tratamentului neaprobat ar putea duce la efecte neaşteptate, nocive, cu rol de coeficienți patogenetici noi, întunecând prognosticul imediat şi/sau tardiv şi aducând medicului acuza de malpraxis. (8)

S-a demonstrat că până la $80 \%$ dintre prescripțiile pentru copii în spital şi în practica generală sunt fie fără aprobare (fără aprobare pentru copii) sau folosite off-label (în afara indicațiilor terapeutice aprobate). (9)

Apare astfel necesitatea imperioasă de a studia indicațiile medicamentelor la populația pediatrică, deoarece datele obținute de la adulți nu pot fi aplicate la copii. Copilul nu este un adult în miniatură; creşterea şi dezvoltarea este însoțită de particularităţi metabolice pe etape de vârstă. Arderile şi asimilările sunt cu atât mai intense cu cât vârsta este mai mică. De aceea medicamentele se dozează pe kilogram de greutate, cu limite specifice precizate în cazul moleculelor bine studiate. Întrucât multe medicamente sunt fără indicații de dozaj aprobate pentru utilizarea pediatrică, în practică se folosesc doze reduse față de cele folosite la adulți. De obicei, scalarea în jos de la dozele de adult, folosind greutatea $(\mathrm{mg} / \mathrm{kg})$ ca şi orientare, duce la o doză prea mică pentru sugari şi copii, deoarece eliminarea medicamentelor nu se schimbă direct proporțional cu greutatea, prin particularități farmacocinetice şi farmacodinamice. (10) Factori cum ar fi înălțimea, suprafața, organogeneza, dezvoltarea enzimelor, legarea medicamentelor de elementele din plasmă şi țesut, dezvoltarea creierului, dezvoltarea fiziologică şi funcţională a organismului, precum şi aspectele psihosociale trebuie luate în considerare în dezvoltarea de noi medicamente pentru copii.

În Europa, doar 35\% dintre medicamente sunt autorizate pentru utilizare la copii. (11) Medicamentele cel mai des folosite pentru aceştia sunt din categoria celor destinate afecțiunilor respiratorii (30\%), antiinfecţioasele de uz sistemic $(28 \%)$ şi cele pentru afecțiunile dermatologice (12\%). (12)

\section{RECOMANDĂRILE OFF-LABEL, UN FENOMEN PE SCARĂ LARGĂ}

Recomandările medicamentelor neautorizate sau cu indicații off-label pentru tratamentul copiilor este un fenomen larg răspândit, prezente în diferite secții de pediatrie ale multor țări. Comparând ambele variante, este mai frecventă utilizarea indicațiilor off-label decât folosirea de medicamente 
neautorizate. Folosirea indicațiilor off-label şi a medicamentelor neautorizate este prezentă în diferite secții de pediatrie şi este răspândită în multe țări.

Potrivit unei cercetări, peste două treimi $(67 \%)$ din 624 de copii admişi la secții în cinci spitale din cinci tări europene au primit prescriptii de medicamente neautorizate sau cu indicatii off-label. Aproximativ 39\% din cele 2.262 de prescripții de medicamente administrate la copii au fost cu indicatiii off-label. Prin urmare, problema de utilizare off-label şi prescrierea de medicamente neautorizate la copii este o problemă în Europa şi necesită acțiune la nivel european. După un alt studiu privind utilizarea indicațiilor off-label la pacienții pediatrici, cel mai vulnerabil grup pediatric este reprezentat de nou-născuții şi sugarii grav bolnavi, având cea mai mare rată de expunere la medicamente insuficient documentate cu privire la eficacitate, siguranță şi dozare; această situație subliniază încă o dată necesitatea existenței unor studii clinice la aceste grupe de vârstă. (13-15)

Un studiu care a antrenat un număr mare de medici în Franța a arătat că $33 \%$ dintre prescripții erau pentru medicamente neautorizate (4\%) sau pentru indicații off-label (29\%). Un procent de 56\% $(\mathrm{N}=550)$ dintre pacienții pediatrici au primit una sau mai multe prescripții cu indicații off-label. (16)

În Marea Britanie, Turner (2008) a arătat că în $25 \%$ dintre prescriptiile de medicamente dintr-un Spital Regional de Copii au fost incluse fie medicamente neautorizate, fie medicamente $\mathrm{cu}$ indicații off-label. În 36\% dintre cazurile internate, pacienţii minori au primit unul sau mai multe tratamente cu medicamente neautorizate sau cu indicatii off-label. (17)

In Statele Unite, un procent de $80 \%$ dintre medicamentele aprobate pe parcursul a cinci ani (1984-1989) nu a avut nici o indicație pediatrică. (18)

În trei secții din Finlanda (Unitatea de Terapie Intensivă Neonatală, secție de Pediatrie Generală şi de Chirurgie Pediatrică) un studiu efectuat în 2009 a arătat faptul că $76 \%$ dintre copiii care primesc o rețetă au avut o prescripție de cel puțin un medicament neautorizat sau cu indicație off-label, frecvența variind: $79 \%$ în Unitatea de Terapie Intensivă Neonatală, 63\% în secția de Pediatrie Generală şi $91 \%$ în secția de Chirurgie Infantilă $(P=0 * 014)$. Dintre toate rețetele (629 de prescripții pentru 108 copii), $51 \%$ au fost cu medicamente aprobate, $36 \%$ cu indicații off-label şi $13 \%$ cu medicamente neautorizate. Studiile internaționale au arătat grade similare de prescriere a medicamentelor neautorizate şi cu indicații off-label. (19)
În Olanda, un studiu de cohortă în secția de pediatrie a unui spital general a relevat faptul că $44 \%$ din rețete erau off-label, iar $28 \%$ erau medicamente neautorizate. $92 \%$ dintre pacienți au primit unul sau mai multe prescripții cu medicamente neautorizate sau cu indicații off-label, iar aceste proporții au fost semnificativ mai mari la copii sub vârsta de 6 luni decât la copii mai mai mari. (20)

În secțiile de pediatrie a două spitale din Israel peste $80 \%$ din totalul pacienților au primit medicamente neautorizate (21). Într-o cercetare anterioară aceeaşi echipă de investigatori a raportat numai $42 \%$ copii trataţi cu medicamente off-label şi/sau neautorizate (22).

Unul dintre numeroase studii desfăşurate în Germania cu privire la utilizarea medicamentelor la copii şi adolescenți a relevat faptul că rata de prevalență a utilizării indicațiilor off-label a fost 40,2\%. Rata este semnificativ mai mare la băieți $(41,4 \%)$, şi la copii cu vârsta între 3-6 ani (48,7\%). Cercetarea a arătat că $30 \%$ din totalul medicamentelor prescrise au fost cu indicații off-label. Utilizare indicațiilor off-label a fost cea mai mare în grupa terapeutică ATC-class „C00 Sistemul Cardiovascular". Pentru toate categoriile de medicamente, la toate grupele de vârstă şi la toate clasele de ATC, subdozare a fost cel mai frecvent motiv pentru utilizarea off-label. (23)

\section{ADMINISTRAREA OFF-LABEL DE SILDENAFIL}

Evaluând 2.130 de prescripții eliberate (secție de cardiologie pediatrică) pe o perioadă de 2 ani pentru 544 de copii, mai mult de jumătate au fost ori $\mathrm{cu}$ medicamente neautorizate $(11 \%)$, ori $\mathrm{cu}$ indicații off-label (47\%). Deşi copiii cu vârsta între 2-11 ani au primit majoritatea prescripțiilor cu medicamente neautorizate (17\%), nou-născuții, deşi nu au primit prescripții cu medicamente neautorizate, au fost lideri (64\%) în utilizarea medicamentelor cu indicații off-label. Acest studiu a arătat că utilizarea medicamentelor neautorizate sau cu indicații off-label, există şi în secțiile de cardiologie pediatrică. (24)

Sildenafil citrat este un medicament creat inițial în 1989 de către o companie farmaceutică ca un medicament pentru tratamentul pacienților cu hipertensiune arterială şi angină pectorală. Deoarece Sildenafil citrat nu a îndeplinit promisiunile ca şi medicament pentru inimă, studiile au fost oprite în 1992. (25)

Terrett şi colaboratorii (1994) au evidențiat că sildenafilul a crescut afluxul de sânge în zona 
penisului şi permite la subiecții de gen masculin să inverseze lipsa capacității de a obține o erecție. Medicamentul acționează prin consolidarea efectului de relaxare a musculaturii netede a oxidului nitric (NO), o substanță chimică, care este eliberată, în mod normal, ca răspuns la stimularea sexuală. Relaxarea musculaturii netede permite un flux de sânge crescut în penis şi care astfel conduce la o erecție atunci când este combinată cu stimul excitant. (26)

Prima etapă a studiilor clinice sub conducerea lui Osterloh (35) a sugerat că substanța a avut un efect redus asupra anginei pectorale, dar că aceasta ar putea induce o erecție semnificativă a penisului. Sildenafil citrat este primul tratament non-chirurgical aprobat pentru disfuncția erectilă, care nu trebuie să fie introdus sau injectat direct în penis pentru a atinge şi a menține o erecție. O mulțime de cercetători au constatat că sildenafil citrat este, de asemenea, eficient în hipertensiunea arterială pulmonară (HTAP). Acesta acționează prin relaxare musculaturii netede din peretele arterial, conducând la scăderea rezistenței arteriale şi la o scădere a presiunea pulmonare. Sildenafil citrat a fost aprobat de FDA pentru această indicație în iunie 2005.

După cum este specificat în toate ghidurile medicale, această substanță nu este indicată pentru utilizare la copii. (27)

Consensul experților în ceea ce priveşte hipertensiune pulmonară (documentul ACCF/AHA 2009 de consens expert) concluzionează că beneficiile utilizării de substanțe, în anumite doze, depăşeşte riscurile la adulti. $\mathrm{Cu}$ toate acestea, folosirea „offlabel" a acestui produs în doze mai mari nu duce la rezultate mai bune, în timp ce efectele secundare sunt considerabile.

Mai multe studii susțin utilizarea de sildenafil la nou-născuţi şi copii cu diferite probleme cardiace. Sunt prezentate cazuri individuale sau studii de cohortă care demonstrează succesul utilizării lui, sildenafil reprezentând o bună opțiune terapeutică. (28-32)

În 2012, după o analiză realizată prin studiile clinice pediatrice asupra mortalității în funcție de doza de sildenafil, FDA a difuzat un comunicat de siguranță împotriva utilizării lui la copiii cu hipertensiune pulmonară.

\section{UTILIZAREA MEDICAMENTULUI SILDENAFIL ÎN ROMÂNIA}

Pe piața de sildenafil din România, în anul 2014 se remarcă o creştere cu $23 \%$ față de anul anterior. (33) Forma de sildenafil aprobată pentru tratamentul hipertensiunii pulmonare este are mai puțin de 1\% cotă de piață din totalul pieței de sildenafil. Este discutabil cât de mare este procentul din celelalte forme, cu doză mică (25 mg) folosit pentru tratamentul disfuncției erectile şi cât de mult este folosit pentru indicații off-label, inclusiv în pediatrie.

Producătorii (de originale şi generice) nu pot promova indicații off-label. $\mathrm{Cu}$ toate acestea, potrivit ARPIM (Asociaţia Română a Producătorilor Internaționali de Medicamente), reprezentanții medicali pot oferi informații despre indicațiile offlabel ca răspuns la o cerere spontană şi explicită din partea unui profesionist (medic/farmacist). (34)

În România nu există nici un studiu amplu cu privire la frecvența indicațiilor off label ale Sildenafilului la copiii cu HTAP; în ultimii doi ani au existat mai multe conflicte, amplu mediatizate, care menționau utilizarea dozelor mici de Sildenafil în spitalele de pediatrie. Prospectul medicamentului specifică clar că produsul nu este aprobat pentru utilizarea sa de către femei şi la copii sub vârsta de 18 ani.

Din punctul de vedere al Agenției Naționale a Medicamentului (ANM) din România, nu sunt interzise indicațiile off-label, acestea reprezentând o opțiune terapeutică a medicului în cazul în care nu există altă alternativă de tratament. Dar, este strict o opțiune pentru care îşi asumă responsabilitatea, bazându-se pe propria sa experiență, respectând tehnicile medicale şi normele profesionale cu privire la utilizarea indicaţiilor off-label.

Conform celor de mai sus, în România - la fel ca în alte țări - utilizarea medicamentului la copii nu este aprobată, nici măcar pentru tratamentul hipertensiunii pulmonare. Cu toate acestea, luând în considerare amploarea indicatiiilor ,off-label“ pentru pacienții pediatrici în Europa, putem estima că în România - unde respectarea cu strictețe a ghidurilor terapeutice este mai puțin consistentă decât în Europa de Vest - pe lângă cazurile mediatizate din ultimii ani din importante spitale de pediatrie din țară, coroborat cu consumul semnificativ de sildenafil de doze mici $25 \mathrm{mg}$ ), putem concluziona că utilizarea indicațiilor off-label de sildenafil la copiii cu tulburări cardiovasculare (cum ar fi hipertensiunea pulmonară) este un fapt, dar unul al cărei magnitudine este insuficient evaluată şi studiată.

\section{CONCLUZII}

Utilizarea medicamentelor cu indicații off-label este un fenomen larg răspândit. Nivelul de expunere este identificat la toate vârstele, cu rată mai mare în copilăria mică. Există două tipuri de soluții care pot 
fi puse în aplicare ca un acord interimar. În primul rând, o listă acceptată pentru utilizările off-label, susținute de dovezi ştiințifice, cel puțin parțial ar ajuta medicii practicanți. A doua soluție, practicată în Franța, este evaluarea şi aprobarea unor indicații off-label specifice de către un grup oficial de experți. (35)
Ambele soluții ar avea efectul de a ajuta medicii în gestionarea paradoxurile etice şi legale asociate cu utilizarea indicațiilor off-label şi înlăturarea dilemelor legate de administrarea medicamentelor la această vârstă. (36) În acelaşi timp, ar duce probabil la tratamente medicale mai sigure şi mai omogene pentru pacienții în cauză din diferite țări. 